\title{
Enterprising Versus Traditional Change Management in a For-Profit University
}

\author{
Marcelline Fusilier ${ }^{1, *}$, Douglas Munro ${ }^{2}$ \\ ${ }^{1}$ College of Business and Economics, American University of Kuwait, P.O. Box 3323, Safat,13034 Kuwait \\ ${ }^{2}$ University of East London, Royal Docks Business School, University Way, London, UK E16 2RD \\ *Corresponding author: mfusilier@auk.edu.kw
}

Copyright (C) 2013 Horizon Research Publishing All rights reserved.

\begin{abstract}
Universities for decades have used bureaucratic organizational structures as they relied on government funding and operated in stable environments. Educational innovations and market developments have prompted the enterprising university movement that emphasizes flexibility, employee involvement, and interface with the external environment. Many administrators and faculty members in universities today received their education and work experience in large state-supported, bureaucratically structured universities. A value for bureaucratic practices may persist as these individuals transition to non-traditional universities operating in dynamic environments. The present study used the case method to explore the extent to which organizational change in a for-profit university in the Middle East was perceived as being managed using a bureaucratic versus an enterprising approach. Semi-structured interviews were conducted with faculty, administrators, and members of the university's board of trustees. Results suggested that the change process was perceived as being bureaucratically managed with administrators making the decisions. This appears contrary to collegial values that characterize universities and inconsistent with the dynamic, open market in which the university operated. Findings provide an example that may help to raise administrative awareness of how past assumptions and behavioral scripts can conflict with an enterprising approach to change management.
\end{abstract}

Keywords Change Management, Enterprising University, Transnational Education, Middle East

\section{Introduction}

The business model for delivery of higher education is undergoing seismic change. Universities have existed as organizations for hundreds of years and are steeped in traditions of faculty autonomy. This unstructured approach to administration that involved few rules was effective when universities were small and admitted only a select few students. With the trend from elite to mass demand for higher education, universities grew to be large organizations and adopted more business-like structures. In recent decades, universities successfully used bureaucratic structures increasingly characterized by managerialism which is the application of business principles to universities $[1,2]$. The purpose of managerialism is to increase efficiency, quantify objectives, standardize services, monitor employee performance, exert control and generally emphasize the primacy of management above all other activities [3].

This approach is also known as the audit culture. Bosco [1] and Kok, Douglas, and McClelland [4] contended that this movement shifted accountability from academic to administrative control. The result was that collegial governance traditions were weakened in favor of the top-down management of bureaucratic organizational structures. Bureaucratic structures were, for the most part, adaptive because universities in the Western world operated in generally predictable environments supported by public funding and growing demand for higher education. Rules and set procedures helped to assure consistent behaviors on the part of faculty and staff. Performance could be defined and relatively unchanging standards set in place. Drawing on Hannan and Freeman [5], the consistent survival of universities with this form of structure created structural inertia - a commitment to this type of organization. Rebora and Turri [6] described structural inertia in a case study of a university.

The recent trends toward reduced government funding for public institutions and for-profit higher education have necessitated greater responsiveness on the part of universities to market forces. While bureaucratic organizational structures served universities well for many years, their external environments are now changing. Clark [7] contended that demands on universities have increased dramatically with increased numbers and diversity of students as well as rapidly changing workforce requirements. The rigidity that can characterize bureaucratic structures may no longer be adaptive in less predictable external environments. Schwarz [8] pointed out that structural inertia can be a deliberate choice. Decision makers attribute value to 
structural inertia, evaluate it as a legitimate structural choice, and support it as a reasonable action during change. This mindset fits with the continuance of traditional bureaucratic university structure and the managerialism associated with it $[1,4]$ even when such a structure may no longer be an adaptive or successful choice.

\subsection{Enterprising Universities}

The concept of enterprising universities developed out of a body of case research originated by Burton Clark [7] on entrepreneurial universities. The spirit of entrepreneurism means that the organization is proactively engaged with its external environment. In changing environments, Hannan and Freeman [5] acknowledge that more adaptive organizational forms are better able to take advantage of new opportunities. Results of case studies suggest that new higher education markets and competition have pressured bureaucratic structures to become more entrepreneurial [9]. A flexible, proactive stance for large, mature organizations is called enterprising, thus the term, "enterprising university" [10]. Such universities respond to external and internal demands effectively by continually reviewing and reforming organizational practices. These universities tend to innovate and use strategy, market oriented governance, and management structure $[7,11]$. This is consistent with recent thinking on the emergent approach to change that views organizational change not as "a series of linear events within a given time period but as a continuous, open-ended process of adaptation to changing circumstances" [12, p. 375]. The emergent approach takes into account the unpredictable nature of change and environmental uncertainty. Examples of innovations that have altered the higher education market include online education providers, partnerships between established Western universities and new institutions in the developing world, and massive open online courses (MOOCs). These and other changes upset the previously predictable environment of higher education.

\subsection{Enterprising versus Bureaucratic/Managerial Universities}

While enterprising and bureaucratic/managerial universities may share some administrative characteristics, an examination of the literature suggests that major differences between them include flexibility and acknowledgement of and engagement with the external environment [4,9]. Bureaucratic/managerial universities tend to focus on hierarchical organizational structure and managing performance in a predictable fashion so that a standardized service is provided $[1,3,4]$. These structures are characterized by chains of command [4] and defined and incentivized quantitative performance objectives [1]. Deem and Brehony [3] used focus groups and semi-structured interviews to assess managerial practices at UK universities. Findings suggested that managerial practices and emphasis on financial targets took primacy over delivery of academic services. The authors called this ideology the "new managerialism." On the basis of survey results of university staff in the UK, Kok et al. [4] similarly found that financial considerations such as effective management of funds and profitability were ranked as being almost as important as teaching quality. Bosco [1] described two major government-mandated higher education initiatives in Hong Kong: use of the one-line budget and the Research Assessment Exercise, both of which appear to contribute to the audit culture in universities.

These structured practices are typical of organizations operating in stable external environments. In such environments, there is often a definable best way to perform the work, and those performance activities can be locked in with clear work roles and performance-contingent reward systems.

By contrast, enterprising universities tend to be oriented toward a changing external environment. Their internal procedures are structured to encourage flexible as opposed to standardized responses to the environment. Clark [9] identified examples based on case research findings. These include use of a flat organizational structure with a steering core that empowers employees to make decisions and a mission statement and strategic plan to relate to the external environment [9]. Moreover, Clark [9] identified the need for academic units to adopt a "stimulated academic heartland" which means that an entrepreneurial culture is developed in which faculty embrace innovation and future opportunities in teaching and research are monitored $[9,13]$. The university as a whole is encouraged to take risks to initiate new practices, according to findings of a study by ECIU Leadership Programme [13]. The ECIU data were collected through interviews with five individuals each at four entrepreneurial universities in the UK.

Specific externally-oriented practices also characterize enterprising universities. These practices include establishing external relationships for development such as alumni outreach, cooperating with industry and other universities, and attracting endowments. The university can also use technology transfer, and attract a high share of graduate students [9]. Clark calls these relationships an expanded developmental periphery. They can be the foundation for a diversified funding base which entails generating income from non-government sources.

The enterprising stance appears to require an adaptive form of organizational structure and an organic design to promote responsiveness to the external environment. Standardized work activities do not fit with a changing environment thus the need for faculty and employee empowerment. Performance objectives cannot be as clearly defined as they are in bureaucratically structured universities because work activities must involve cooperation, risk taking, and flexibility. Clark [7] summarized Shattock's research on inhibitors of university change, concluding that bureaucratic management structure, culture, and hierarchy stood in the way of adaptive change.

The movement of universities away from traditional 
bureaucratic structures to more flexible approaches parallels that in many industries. On the basis of data spanning 20 years for 438 Italian manufacturing plants, Colombo and DelMastro [14] found that flatter structures were associated with more innovation. Garg and Singh [15] reviewed organizational change literature and concluded that organizational structure must support entrepreneurial management. A questionnaire study compared eight academic and eight business organizations that had undergone transformation within the past five years [16]. Findings revealed that employees in the academic organizations tended to perceive their change leaders as providing greater support, using more employee participation, communicating more about the change, and developing a shared vision [16].

Anomalies, or problems that threaten the core functions of organizations, can depress performance and therefore necessitate change [17]. Based on a case study of organizational change in the Middle East Technical University in Turkey, Simsek and Aytemiz [17], suggested that anomalies can arise when there is a disconnect between the cognitive image of reality and a university's environment. University faculty and administrators who have spent their lives in bureaucratically structured universities may not have a cognitive image of reality that fits with a changing environment such as that which surrounds for-profit, transnational higher education outside of the Western world.

\subsection{Purpose of the Present Study}

Universities' effectiveness and relevance appears to increasingly derive from change management decisions based on awareness of the internal and external environments. The present study therefore explored the extent to which administrators and faculty took an enterprising versus bureaucratic/managerial approach to managing the structural change in a dynamic higher education environment. Are the organization members' perceptions and behaviors simply a carry-over from the large state-supported, bureaucratically structured universities where many of these individuals received their education and past work experience? If that is the case, these individuals may be making a deliberate choice for bureaucratic structural inertia. Or, do these perceptions and behaviors suggest an awareness of the new environment and the struggle to develop an engaged, enterprising focus in relating to it? Findings of the study may serve as a specific example that may raise awareness of how past assumptions and behavioral scripts can affect an enterprising approach to change management.

Consistent with a number of previous studies in this area $[6,7,9,17,18]$ the present study used a case approach to investigate faculty and administrator perceptions of a structural organizational change. The context was non-traditional: a transnational, for-profit higher education provider in the Middle East. The university re-structured to create a new business college. This university was suited to the purpose of the present research for several reasons: (a) It had recently undergone a major organizational change, restructuring. (b) It operated in a competitive, dynamic higher education market. (c) The faculty and administrators were nearly all educated and had previous experience in large, traditional, government-supported universities in the Western World. (d) While much of the previous literature has investigated universities in the USA and UK, the present study focuses on a different geographic region, the Middle East, consistent with Simsek and Aytemiz [17].

The availability of higher education is growing rapidly in the Middle East: over half of the 57 transnational higher education institutions located there were established since the year 2000 [19]. This is a relatively sudden entry of providers attracted by the regional market opportunity for higher education. Government-supported universities have not been able to meet demand in recent decades therefore private, for-profit providers have offered degree programs. The for-profit providers lack the government support accorded to state universities and therefore must compete in a more open market. Wilkins [20] and Becker [21] reported that the supply of higher education may exceed demand in the United Arab Emirates (UAE) causing increased competition for students. Some higher education providers have failed, causing them to withdraw from the dynamic market of the UAE [22,23]. Examples include the campuses affiliated with Michigan State University (Dubai), Australian-based University of Southern Queensland (Dubai) and George Mason University (Ras Al Khaimah). Becker [21] contended that the international branch campus closures were caused by marketing issues but administrative practices almost certainly contributed. The effectiveness of universities' change management decisions and practices therefore appear critical to their survival.

\section{Method}

Interview data were collected at a transnational, for-profit university in the Middle East. The university was established in the early 2000s and partnered with a major Western university. It is an undergraduate institution with an enrollment of over 2000 students.

\subsection{Sample}

Interviews were requested with 20 individuals. Eighteen agreed to participate for a 90 percent response rate. Two of the participants served on the university board of trustees; five were administrators including the university president, two deans, two vice presidents, and a finance director. The remaining participants were faculty members. An administrator and a faculty member chose not to be interviewed. Reasons for non-participation were as follows: the administrator said that he was not involved with the structural change and therefore felt that he could not contribute to the study. The faculty member simply refused 
to participate without explanation.

\subsection{Procedure}

Semi-structured interviews were conducted that included general questions about the change process for the creation of the business college. The questions pertained to the planning, implementation, and evaluation of the structural change. Terms such as entrepreneurism, bureaucracy, and managerialism were not used to avoid leading the responses. Eleven of the interviews were conducted individually. The interviews were scheduled at times convenient for the respondents. Five of the faculty members participated in a group interview and one who was not able to attend a session chose to submit responses in writing. One of the administrators also responded in writing. All interviews were conducted by either a faculty member or an individual employed by an outside marketing firm. Both were experienced in collecting interview data. Interviews were audio recorded and transcribed. The transcriptions were then coded.

\subsection{Coding}

Based on previous literature, four characteristics each were identified for enterprising and bureaucratic/managerial universities. Characteristics that appeared logically related were grouped together. For the enterprising category, the characteristics were based on Clark's [9] features of entrepreneurial universities: strengthened steering core, expanded developmental periphery, diversified funding base, and stimulated academic heartland. For the bureaucratic/managerial category, the following characteristics were identified: structured organizational hierarchy, predictability, quantitative objectives, and administrative power. The administrative power characteristic conveyed the extent to which administrators had power and control as opposed to academics. Details of the coding categories are listed in the Appendix.

Some characteristics identified in the literature were either not relevant to the present case or were not reflected in any of the interview statements. Such characteristics were not included in the coding categories. For example, Clark [9] and ECIU [13] identified a high share of master/postgraduate students as a feature of enterprising universities. The university in the present study did not have graduate programs therefore this characteristic was not relevant and was not included in the coding categories.

Statements in the interview transcripts that pertained to the structural change were coded according to whether they reflected one of the categories and if so, the extent of the characteristic. Individual statements were coded as only one characteristic. No statements were coded as reflecting two or more characteristics. Extent of a characteristic was coded according to values from zero to two. A zero meant that the characteristic mentioned was absent. For example, if a respondent said that there was no faculty participation in the restructuring, the category for strengthened steering core would receive a score of zero. If an interview statement reflected some of a characteristic, it would be coded as one. A high degree of the characteristic was coded as two. Examples for participation: a score of one would be assigned if the respondent said that a few employees were allowed to participate but not all. A score of two would be assigned if the statement indicated full participation in the restructuring. Three individuals coded the data according to the framework described above and in the Appendix. There was perfect agreement across the coders for assignment of interview statements to enterprising versus bureaucratic categories. Inter-coder agreement on the extent of the characteristics (three levels) was measured using Cohen's kappa for all possible pairs of coders. The kappa values ranged from .94 to .96 indicating that the strength of agreement is high [24].

\subsection{Analyses}

Qualitative and quantitative analyses were conducted. Quantitative analyses involved frequency counts and comparisons across categories. The number of comments reflecting each characteristic at each level (0 to 2) was tabulated. The numbers of comments were also multiplied by their corresponding score. For example, three comments at level 2 of a characteristic would yield a product score of six. The number of comments multiplied by their level suggested the extent to which a characteristic was reflected in the data. These scores enabled comparisons across the enterprising versus bureaucratic/managerial categories. The qualitative analyses were conducted by examining interview statements for descriptions of enterprising versus bureaucratic/managerial university characteristics.

\section{Results}

Quantitative results are explained in this section. Qualitative results are included in the Discussion section of the paper. Total comments that were relevant and therefore coded for the study was 265 .

The average number of comments per interview was 16.5 and standard deviation was 25.18 . Comments that could be coded ranged from seven to 30 per respondent. A total of 151 comments from the interviews were coded as enterprising university characteristics however 52 of the comments were coded as zero, indicating that an enterprising characteristic was mentioned as being absent. Figure 1 shows the number of interview comments coded as reflecting each of the enterprising categories and their extent ( 0 to 2$)$. A total of 114 comments appeared to reflect bureaucratic/managerial university characteristics. Only four were coded as zero which suggests that the majority of the comments reflected bureaucratic/managerial practices associated with the organizational change. See Figure 2 for the numbers of interview comments concerning bureaucratic/managerial characteristics. 
Each score was multiplied by its corresponding value denoting the extent of the characteristic. Product scores were summed to arrive at two totals: one for the enterprising category and the other for the bureaucratic/managerial category. This was a measure of the number and extent to which all interview comments reflected each of the categories. The summed product score total for the enterprising category was 159; that for the bureaucratic/managerial category was 198 . A chi-square test was applied to determine whether the values differed. The result was statistically significant $\left(\chi^{2}=4.26, \mathrm{df}=1, \mathrm{p}<.05\right)$ which suggests that the change in organizational structure was percei ved to be managed more bureaucratically as opposed to an enterprising approach.

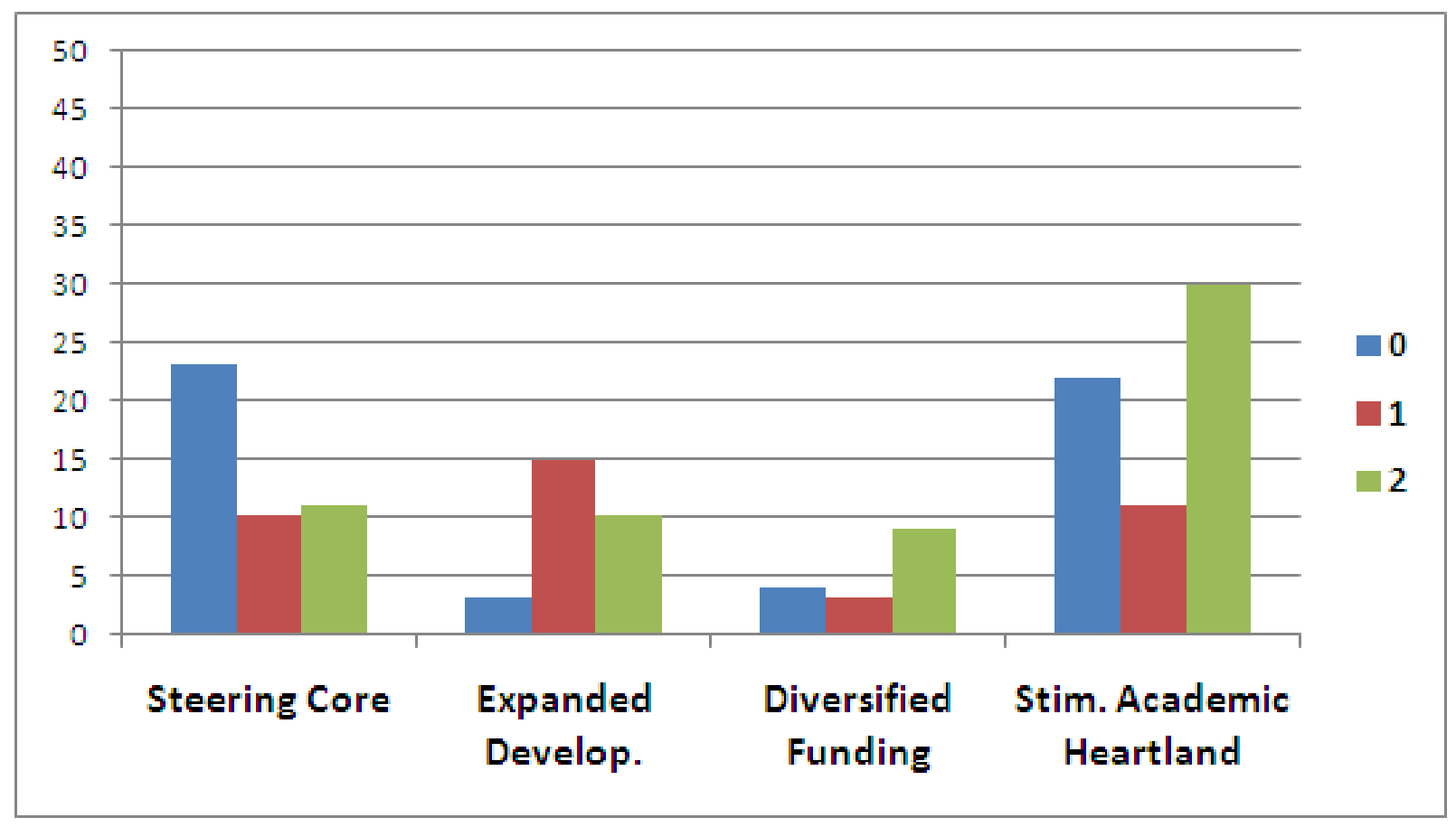

Figure 1. Number of Statements at each level for Enterprising University Characteristics

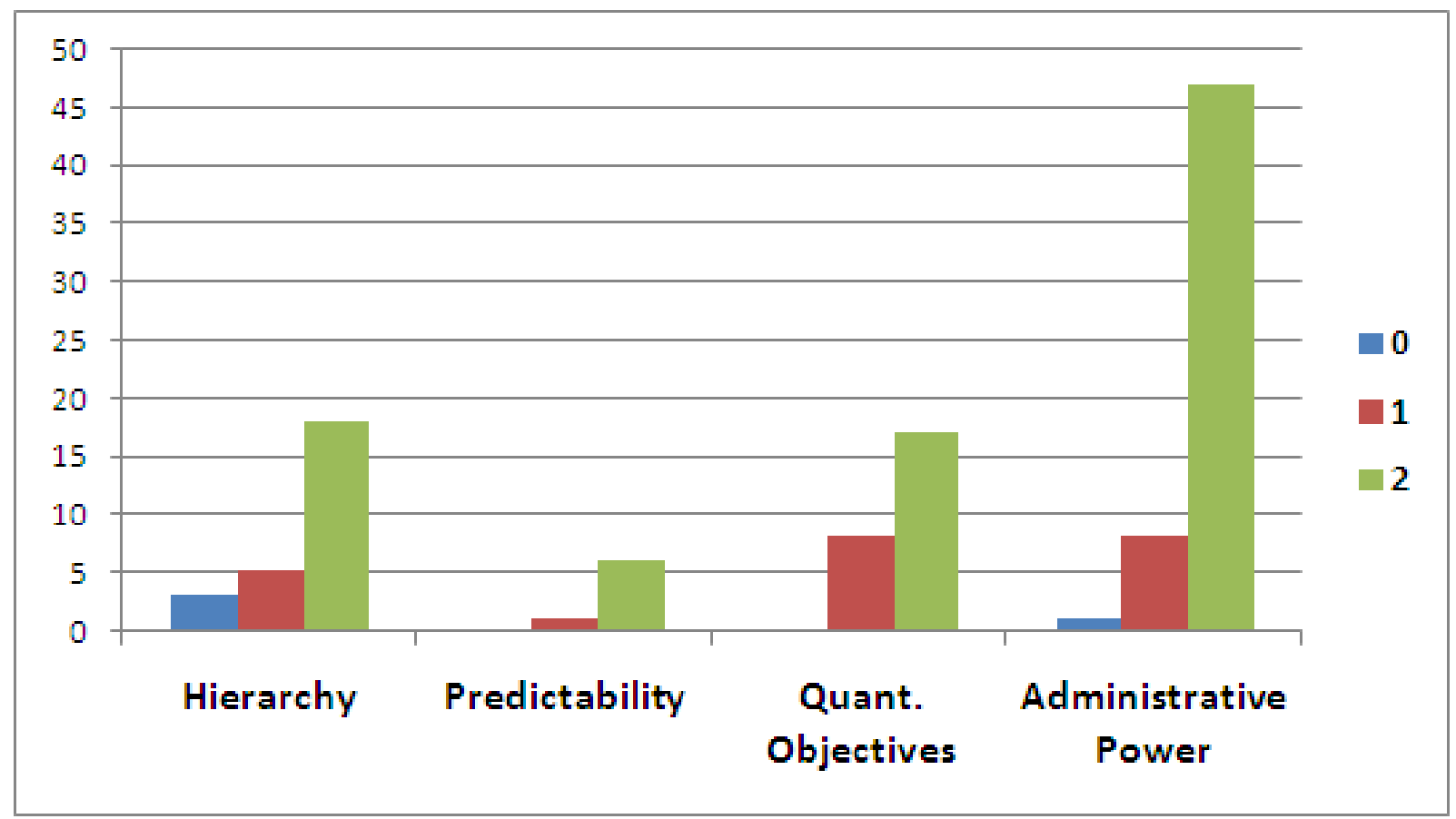

Figure 2. Number of Statements at each level for Bureaucratic/Managerial University Characteristics 


\section{Discussion}

The case results suggested conflict between the involvement that internal stakeholders wanted in the change process and the top-down approach used for its management. On one hand, the quantitative data indicated relatively little employee participation in the structural change to create the business college. Decisions were apparently seen as being made by administration. This finding tends to be consistent with the notion of structural inertia. This transnational, for-profit university in the Middle East appeared to be managed using traditional, bureaucratic procedures rather than an enterprising approach. This seems inconsistent with the external environment of the university which is competitive and growing both in terms of potential students and competition from other higher education providers in the region.

On the other hand, a fairly large number of interview comments suggested a value for a stimulated academic heartland which entails an enterprising culture and opportunities to monitor the external environment. This suggests that those involved saw enterprising aspects of the organizational change. They seemed to attach value to enterprising concepts in contrast to the apparently top-down management style they were reportedly experiencing. In this particular institution, characteristics of enterprising and bureaucratic universities appeared to exist simultaneously to some extent. The interview comments on a stimulated academic heartland turned out to be an indication of the future. Soon after the data were collected, the top administrators of the university experienced involuntary turnover. The change in leadership could open the way for a culture of more participative decision making and enterprising behavior on the part of employees and the organization as a whole. A more flexible, inclusive approach to change in the future could help the university to better adapt to its external environment and move it beyond the structural inertia that has characterized universities in recent decades.

\subsection{Administrative Power and Hierarchy}

Examples of interview comments for each of the categories are presented below. The bureaucratic/managerial characteristic of administrative over academic power received the most comments. A quotation from a faculty member that exemplifies this characteristic is:

"It all seemed to happen right at the same time and that's how the change was implemented. There was no formal announcement as far as I know or an explanation of why it was happening. I guess I just assumed it was

happening on the board level that they were making those sorts of decisions."A related enterprising characteristic is lack of participation (score of 0 ) for the strengthened steering core. Example quotations from faculty members are:

"We don't have an avenue to voice any concern."

"... it wasn't a very smooth transition and it has to do with transparency and communication - those are problems not with the administration and business but with the whole university in general, you just hear things after the fact, and we're just supposed to put up and shut up, and it's hard for us to do that, we are paid to talk, we are paid to have an opinion and they're keeping us down."

Some administrators also expressed the view that the change was implemented without their participation. The following is from an administrator:

"I guess this is probably really sad to say but there wasn't, at least from my standpoint, a lot of involvement in terms of the decision for the college, how it was going to be implemented, whether there was a transition, or like I said, one day it's here and one day it's not - nothing to do with it, nothing."

A board member observed the management hierarchy in the university. This is a characteristic of bureaucratic/managerial universities.

"I think, because they didn't have anybody who knew what to do, they created bureaucracy. I'm not going to say high administrators. They created bureaucracy as a way to get from A to B - getting something done."

An administrator explained the emphasis on and need for structural hierarchy in the university as follows:

"You can't compare you know the administrative operations here to that of universities in the States - I'll just give you a simple example, in the U.S. if a university wants to offer a new major, that's it. Faculty would convene, develop the curriculum, financial resources are taken into consideration if it's approved - that's it. ...Here you have to deal with the [government regulatory agency], you need approvals...staff, administration has to do these things..."

Slaughter and Rhodes [25] noted that the numbers of university middle managers have also expanded in the U.S. for purposes of supervising commercial endeavors and engaging various stakeholder groups. More funding is therefore allocated to administration. This, along with the growth of such positions may also account for the apparent power of administration versus academics.

Clark [9] concluded that "entrepreneurialism works when it is significantly collegial" (p. 173). The large number of comments in the present data reporting administrative power and an absence of a strengthened steering core suggest a lack of collegial decision making which presents a barrier to an enterprising university stance. Clark [7] also contended that bureaucratic management and hierarchy can act as inhibitors to change, however in the present case, the structural change actually took place. Organization members may have been more accepting of the change had a participative approach been used. Participative decision-making may have been sacrificed by the administration in the interest of speed. While this may be effective in other industries, it may not be suited to universities with their long history of collegiality.

\subsection{Enterprising Characteristics}

The enterprising characteristic of stimulated academic 
heartland includes entrepreneurial culture, innovation, and monitoring future opportunities. The following quotations are from a faculty member and a dean concerning future opportunities:

"I foresee if we go through the higher accreditation and we enforce the proposals we have right now to improve quality, it's going to be an elite program here."

"[The university] has the opportunity to become a leading source of business acumen in [the country]."

The quotation below is from a faculty member. It was coded to reflect a zero-level or lack of a stimulated academic heartland:

"...my opinion is we are losing our edge..."

The following is an example of the expanded developmental periphery, another aspect of enterprising universities. It was provided by a faculty member.

"[The foreign partner university] provided some valuable feedback..."

A faculty member provided the following comment which was coded to reflect the enterprising characteristic of a diversified funding base:

"Ideally, I would like the school to be non-profit and to have enough, maybe large enough endowment to be self-sustained. If that means someone can, let's say maybe put a multi-million endowment [from a donor]. Make it available to the school in exchange for their name on the College..."

\subsection{Bureaucratic/managerial Characteristics}

The bureaucratic/managerial characteristic of quantitative objectives and attaining financial targets can be seen in the following quotation from a faculty member:

“...we keep growing, let's put it that way. We grow, we have the same printers; we grow, we have the same copier; we grow, we don't have assistants. I used to teach 25 students, now I teach 40 students...I mean, you need to grow when the university grows, you cannot stay small and the university grows..."

A board member provided an example of the predictability that may be embedded in universities and suggests the structured use of rules:

“...If you do implement change, you know, there are some basic rules in academics, we can't go too fast because when students come in, in any given year, we have an implicit contract not to change the rules of the game for four years and so you have to move somewhat slowly, even if you can think of a brilliant better way of doing things, you have to do it by degrees."

\subsection{Enterprising and Bureaucratic/managerial Characteristics}

The large number and variety of comments of an enterprising nature suggests that the respondents had some notion of an enterprising university even as they perceived the university being characterized, to some extent, by bureaucratic/managerial characteristics. A value was apparently expressed for a strengthened steering core and stimulated academic heartland. Despite the fact that many had received their education and past experience in traditionally structured, government supported universities, there did not appear to be comments in favor of deliberate structural inertia without consideration of the open higher education market in the Middle East. Rae, Gee, and Moon (24) provided specific guidelines on how to develop an enterprising culture in a university based on a case study of the University of Derby.

\section{Conclusion}

The present study provides a specific example of conflict between traditional, bureaucratic operations and the need for enterprsing change management. This case may resonate with university administrators and faculty as they confront the challenge of organizational interface with dynamic external environments. Clark [7] pointed out that because demands on universities are mounting and often not well understood, organizational response capabilities are threatened. Clark [7] further noted that confidence has been eroding in the traditional ways of structuring and operating universities. This is manifested in the trend toward structural change in universities that often takes the form of differentiation. The present case is an example of such structural differentiation: creating a new unit specifically to deal with business students. This differentiation may help the university to better address the demand from its external environment for more business education in the Middle East.

The exit of the top administrators after the structural change could have been a result of the lack of fit between the top-down management of the change and the enterprising values that were expressed. The conflict might have been effectively addressed by making fuller use of the organization's intellectual capital and effective gathering, use, and sharing of information, particularly from the external environment.

\subsection{Contribution of the Study}

As a case study of one organization, the present results may not be appropriately generalized to university administrative practices. The main value of case findings is to generate development of (a) hypotheses that can be tested in future research and (b) discussion and consideration of the issues from an administrative practice standpoint. Points for further consideration in research and practice are identified below.

1. Bureaucratic/managerial and enterprising characteristics of the organizational change in the present case appeared to coexist. Does this co-existence help or hinder the change process? While the inherent conflict may spark creativity, it might alternatively contribute to an impasse in change progress. 
2. To what extent does structural inertia exist in other universities? If structural inertia interferes with enterprising initiatives, how might it be managed?

3. In the present case, diagnosis of and sensitivity to internal stakeholder needs appeared necessary yet was missing. To what extent and why might this important step in the change management process be overlooked in other universities as they implement organizational changes?

Future quantitative studies could involve samples of multiple universities for comparisons of the outcomes of bureaucratic/managerial and enterprising approaches to management. Outcomes could include internal factors such as staff productivity and work satisfaction as well as external indicators such as student satisfaction, learning outcomes, university reputation, and market competitiveness.
Almost 10 years after the publication of Clark's [9] case studies on factors that inhibit universities from becoming entrepreneurial, the present data suggest that, at least in this case, there still exists a hierarchical division that can cut academic staff out of decision making and shift power to management. The present case demonstrates that both enterprising and bureaucratic/managerial actions exist even in a newer university operating in a non-traditional environment.

\section{Acknowledgements}

The authors wish to thank Ms. Mona Hallaq and Ms. Leen Taha for their help in data collection and transcription.

\section{Appendix}

\section{Coding Categories and Characteristics of each}

\begin{tabular}{|c|c|}
\hline $\begin{array}{c}\text { Enterprising characteristics } \\
\text { (All characteristics were adapted from Clark }[7,9])\end{array}$ & Bureaucratic/managerial characteristics \\
\hline $\begin{array}{l}\text { 1. Strengthened steering core (decision body for change) } \\
\text { - Participation in decision making } \\
\text { - Collective mindset and practice }\end{array}$ & $\begin{array}{l}\text { 1. Structural hierarchy } \\
\text { - Clear lines of responsibility highlighting accountability and identifying } \\
\text { individual culpability [4] } \\
\text { - Structured management hierarchy that emphasizes seniority and chains of } \\
\text { command [4] }\end{array}$ \\
\hline $\begin{array}{l}\text { 2. Expanded developmental periphery (external } \\
\text { partnerships) } \\
\text { - Cooperation with industry and other universities }\end{array}$ & 2. Predictability [1] \\
\hline $\begin{array}{l}\text { 3. Diversified funding base } \\
\text { - Funding from a variety of sources }\end{array}$ & $\begin{array}{l}\text { 3. Quantitative objectives [1] } \\
\text { - Monitoring employee performance [3] } \\
\text { - Attainment of financial and other targets [3] }\end{array}$ \\
\hline $\begin{array}{l}\text { 4. Stimulated academic heartland } \\
\text { - Entrepreneurial culture } \\
\text { - Innovation } \\
\text { - Monitoring future opportunities in teaching and research }\end{array}$ & $\begin{array}{l}\text { 4. Administrative power } \\
\text { - Emphasizing primacy of management above all other activities [3] } \\
\text { - Administrators have power and control as opposed to academics. [3] }\end{array}$ \\
\hline
\end{tabular}

\section{REFERENCES}

[1] J. Bosco. The formula as a managerial tool: Audit culture in Hong Kong, Journal of Workplace Rights, Vol. 16, No. 3-4, 383-403, 2012.

[2] S. Smeenk, C. Teelken, R. Eisinga, H. Doorewaard. Managerialism, organizational commitment, and quality of job performances among European university employees, Research in Higher Education, Vol. 50, No. 6, 589-607, 2009.

[3] R. Deem, K..J. Brehony. Management as ideology: The case of 'new managerialism' in higher education, Oxford Review of Education, Vol. 31, No.2, 217-235, 2005.

[4] S.K., Kok, A. Douglas, B. McClelland. Shifting higher education management: Examining the organizational changes among various UK university types, The
International Journal of Learning, Vol. 15, No. 4, 227-239, 2008 .

[5] M.T. Hannan, J. Freeman. Structural inertia and organizational change, American Sociological Review, Vol. 49, No. 2, 149-164, 1984.

[6] G. Rebora, M. Turri. Change management in universities: More a question of balance than a pathway, Tertiary Education and Management, Vol. 16, No. 4, 285-302, 2010.

[7] B.R. Clark. Creating entrepreneurial universities, organizatio nal pathways of transformation. London, UK: Pergamon, 1998 .

[8] G.M. Schwarz. The logic of Deliberate structural inertia., Journal of Management, Vol. 38, No. 2, 547-572, 2010.

[9] B.R. Clark. Sustaining change in universities, continuities in case studies and concepts. Maidenhead, UK: Open University Press, 2004.

[10] Enterprising Universities (2013). Available online at: http://www.enterprisinguniversities.co.uk/ Accessed 8 June 
2013.

[11] Pietsch, T. (2011). Specialisation is back on the HE agenda, but not for the first time. Higher Education Network, Available online at: http://www.guardian.co.uk/higher-educa tion-network/blog/2011/jul/06/universities-specialisation-hig her-education Accessed 8 June 2013.

[12] R.T. By. Organizational change management: A critical review, Journal of Change Management, Vol. 5, No.4, 369-380, 2005.

[13] ECIU, (2004/2005). Entrepreneurial university: Myth or reality? ECIU Leadership Programme. Available online at: http://vbn.aau.dk/files/86749/Entrepreneurial\%20University \%20-\%20Myth\%20or\%20Reality.pdf Accessed 8 June 8, 2013.

[14] M.G. Colombo, M. DelMastro. The determinants of organizational change and structural inertia: Technological and organizational factors, Journal of Economics \& Management Strategy, Vol. 11, No. 4, 595-635, 2002.

[15] R.K. Garg, T.P. Singh. Management of change - a comprehensive review, Global Journal of Flexible Systems Management. Vol. 7, No. 1-2, 45-60, 2006.

[16] R.M. Hechanova, R. Cementina-Olpoc. Transformational leadership, change management, and commitment to change: A comparison of academic and business organizations, Asia-Pacific Education Researcher, Vol. 22, No. 1, 11-19, 2013.

[17] H. Simsek, D. Aytemiz. Anomaly-based change in higher education: The case of a large, Turkish public university, Higher Education, Vol. 36, No. 2, 155-159, 1998.
[18] D. Rae, S. Gee, R. Moon. Creating an enterprise culture in a university, Industry \& Higher Education, Vol. 23, No. 3, 183-197, 2009.

[19] C. Miller-Idriss, E. Hanauer. Transnational higher education: Offshore campuses in the Middle East, Comparative Education, Vol. 47, No. 2, 181-207, 2011.

[20] S. Wilkins. Higher education in the United Arab Emirates: An analysis of the outcomes of significant increases in supply and competition, Journal of Higher Education Policy and Management, Vol. 32, No. 4, 389-4000, 2010.

[21] R.F.J. Becker. International Brand Campuses: Markets and Strategies. London, UK: The Observatory on Borderless Higher Education. 2009.

[22] M.A. Tétreault. Soft power goes abroad: The transplant university as a western outpost in the Arab Gulf states. In K.L. Kleypas \& J.I. McDougall (eds.), The American-Style University at Large, Plymouth, UK: Lexington Books, 2012.

[23] S. Wilkins, J. Huisman. Student recruitment at international branch campuses: Can they compete in the global market? Journal of Studies in International Education, Vol. 15, No. 3, 299-316, 2011.

[24] GraphPad software. (2013). Available online at: http:/graphpad.com/quickcalcs/kappa1/?K=3 Accessed 1 September 2013.

[25] S. Slaughter, G. Rhoades. Academic Capitalism and the New Economy. Baltimore, MD, USA: Johns Hopkins University Press, 2004 